\title{
Fatores associados à mortalidade em pacientes clínicos em hospital secundário do interior do Brasil
}

\author{
Diogo, L.P.; Bahlis, L.F.; Rohr, D.; Soares, V.S.; Waldemar, F.S.; Ernandorena, \\ J.; Wajner, A.; \\ Apresentador: Daiana Rohr
}

\section{Resumo}

Introdução: Esforços para redução de mortalidade em pacientes internados se iniciam pelo conhecimento de seus fatores de risco. Entretanto, não encontramos na literatura descrição desses fatores de risco em hospitais do interior do Brasil. Objetivos: identificar fatores associados a mortalidade em pacientes clínicos internados. Método: foi realizada coorte retrospectiva dos pacientes internados em enfermaria clínica do Hospital Montenegro. Os dados foram retirados da base de dados do serviço de medicina hospitalar, que contém informações sócio-demográficas e clínicas dos pacientes. As informações são coletas no momento da alta por coletadora treinada, por meio de revisão de prontuário e complementadas pelo médico assistente. Após, é feita revisão dos dados por médico independente para conferência do preenchimento. Os dados são digitados em planilha Excel, sendo posteriormente importados para SPSS para análise estatística. Foi realizada estatística descritiva, além de regressão logística stepwise foward. Resultados: o período de coleta foi de maio de 2013 a abril de 2014. O total de pacientes analisados foi de 1539. A mortalidade foi de 7.9\% (117 óbitos). Os fatores de risco encontrados em nossa população para mortalidade foram: escore de Charlson maior do que 3 (OR 2,81 IC 1,62-4,88 p? <0,0001) necessidade do uso de antibióticos (OR 2,23 IC $1,08-4,58 \mathrm{p} ?<0,029)$ cultura positiva para germe multirresistente (OR 2,84 IC 1,48-5,6 p? <0,002) e Swab de vigilância positivo para germe multirresistente (OR 2,25 IC 1,22-4,16 p?0,009). Conclusão: conhecer fatores de risco é fundamental para que se possa intervir sobre os mesmos. Muitas vezes, fatores de risco em populações de hospitais terciários não são sobreponíveis a hospitais secundários fora das grandes metrópoles. Em nosso estudo, encontramos fatores de risco já conhecidos na literatura, o que reforça nossos achados.

\section{Referência:}

Diogo, L.P.; Bahlis, L.F.; Rohr, D.; Soares, V.S.; Waldemar, F.S.; Ernandorena, J.; Wajner, A.;. Fatores associados à mortalidade em pacientes clínicos em hospital secundário do interior do Brasil. In: II Congresso Brasileiro de Medicina Hospitalar - II CBMH [= Blucher Medical Proceedings, vol.1, num.5] São Paulo: Editora Blucher, 2014. p.87

DOI 10.5151/medpro-II-cbmh-085 